\title{
Techniques for Optimal Maintenance Scheduling
}

\author{
${ }^{1}$ Boniface Onyemaechi Anyaka, ${ }^{2}$ Mbunwe Josphine M. \\ ${ }^{1,2}$ Department of Electrical Engineering University of Nigeria, Nsukka
}

\begin{abstract}
Electric Power systems are composed of a very large number of subsystems and components which are subject to failures. The consequences of a failure of a component or subsystem may range from no effect at all on the operation of the system to wide-scale power interruptions caused by system instability. The cost associated with component failure may depend on the severity of the failure and on the corrective action undertaken to remedy the situation. In most of the cases, there will be some cost associated with the use of manpower and equipment. To solve this problem, a mathematical optimization technique was adopted to determine the optimum preventive maintenance periods and the number of men required to perform the Preventive maintenance such that the total maintenance cost is minimized. Results from the search technique, demonstrated a minimized maintenance cost rate.

Key Words: Preventive Maintenance, Inspection, Replacement, Availability, Breakdown
\end{abstract}

\section{Introduction}

The maintenance of any engineering system consists of performing three main functions which include [1,2]:

- Corrective maintenance, consisting of recognition or detection, location or diagnosis, correction or repair/replacement, and verification or checking of scheduled, emergency failure of components or equipment.

- Setting up and performing scheduled periodic preventive inspections, replacements or repairs.

- Repair activities in a central maintenance facility on failed and replaced items arriving from various operating stations.

Usually a group of skilled technicians or electricians will be assigned to carry out the first two functions. Their responsibility is to perform unscheduled (emergency) repair work anywhere in the system and scheduled preventive maintenance of the components of the system. The two actions may be grouped as on-site maintenance [2].

The objective of work scheduling is to ensure that the maintenance operations are carried out at an optimum level [3]. The amount of work that may actually be scheduled depends on the type of industry. In some processes, industries unit production equipment may be operated until breakdown [4]. The emergency situation created is then given attention, thus yielding optimum production. In other types of industries regular Preventive Maintenance (PM) when properly scheduled yields optimum production [5]. It is therefore important to study the particular situation under operation.

It is evident from the above that there are two main categories of jobs, that is, emergency and scheduled maintenance $[1,2,6]$.

Emergency work interrupts all other work. The most competent work crews are assigned to such maintenance work whose objective is to restore production as quickly as possible. An emergency may constitute an actual breakdown, a situation that will inevitably lead to a breakdown, or an unsafe situation that is likely to lead to human injury or loss of life. The problem here is that the supervisor should have an estimate of the number of hours that are most likely to be used on emergencies. This way the hours available per week for scheduled work can be estimated. Here historical data taken from records on emergencies and their time for repairs are used. Since these data may vary from week to week, a moving average is generally used. For example, generally a 13-week moving average is used to keep track of trends in emergency and scheduled maintenance hours $[7,8]$.

Scheduled maintenance may be divided into two groups, that is, routine or project oriented maintenance such as minor installations, modifications, relocations, etc. and preventive maintenance $[9,10]$. If the average man-hours required per week for preventive maintenance are known, then it is possible to finally estimate the hours to be scheduled as follows.

Electrical craftsmen

Daily hour each man

Total daily hours
(4 Job Turnaround)

$=\quad 2$ weeks

$=8$

32 
Less:

Fixed station assignment

$\begin{array}{lll}= & 2 & \\ = & 4 & \\ = & 8 & \\ & = & 2 \\ = & 16 & \\ = & 80 \\ = & 2 \\ & = & 16\end{array}$

Preventive maintenance

Emergency work

Absenteeism

Daily man-hours available

Weekly man-hours available

Job turnaround time

Backlog level in man-hours

$=16$

The backlog level is a means of ensuring that all crafts are properly man loaded [11]. The turnaround time is determined from historical data or from data obtained by standard work measurement techniques. The development of the backlog of work for each craft makes scheduling more effective in that greater backlogs provide a better opportunity to match up and schedule the work force $[12,13]$.

\section{Priority System}

All jobs must have a priority classification. The broad boundaries of the classifications are determined based on operation in each industry. Jobs within each priority group will be attended to on a first in first out basis. This however may not strictly apply to emergencies which must be attended to at once but on met. For instance a plant wide power failure will have a higher priority than the breakdown of unit equipment even though the latter may have occurred first. Similarly the leakage toxic or inflammable liquids or gas may attract even higher priority due to their health and safety hazards to the work force or neighbouring community.

\section{Maintenance Work Request Flow Chart}

The work flow and its management are typically shown in the flow chart following in Fig.1.

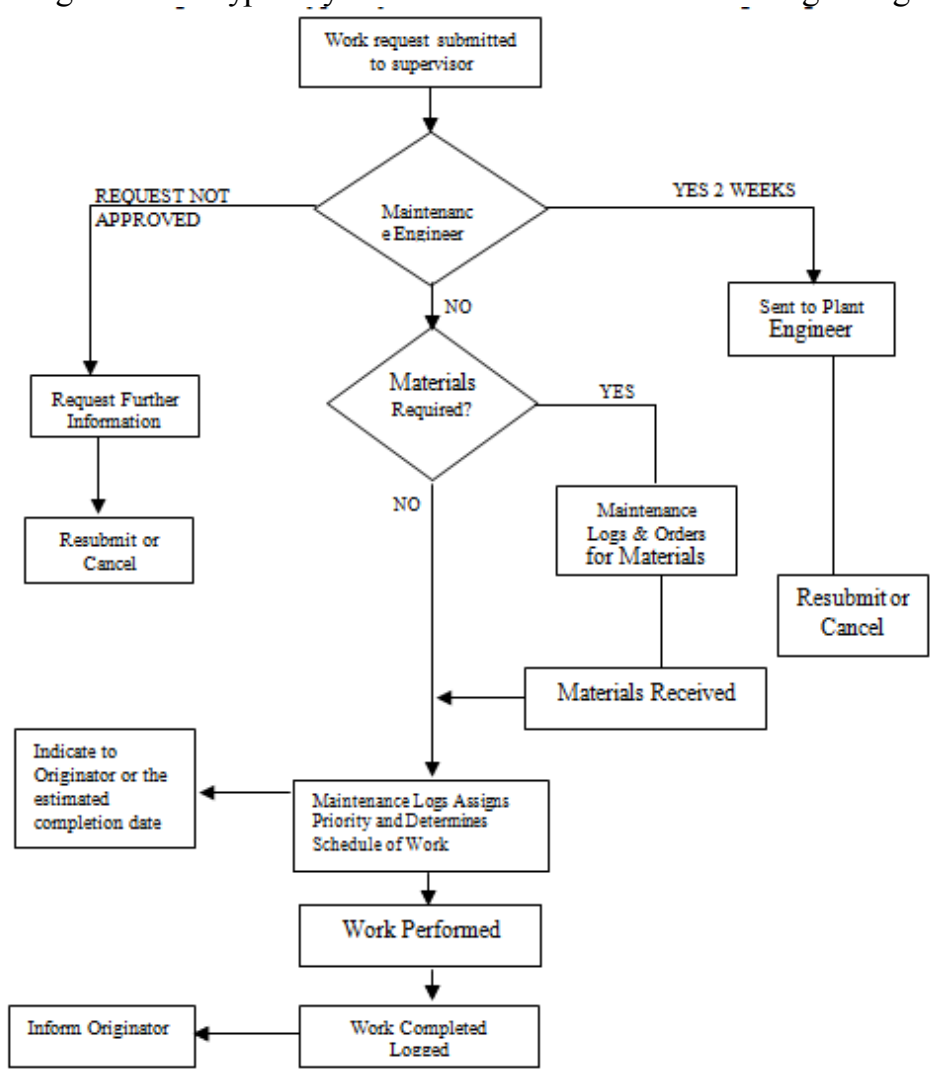

Fig. 1: Maintenance with Request Flow Chart

The key in this work flow chart is the maintenance job priority assignment task which assigns jobs to the various craftsmen in a queue; this technique may be optimal for a large number of establishments.

Preventive maintenance and its frequency in the presence of breakdowns for each group of equipment poses problems of scheduling that need special attention. It is noted that the operation or availability or a piece of equipment between PM periods may be punctuated by breakdown repair periods. A mathematical 
optimization technique may be adopted to determine the optimum PM periods and the number of men required to perform the PM as well as repair the broken down equipment, such that the total maintenance cost is minimized. A mathematical programming technique is usually adopted by maintenance management consultants due to its ability to take most of the operating variables and factors into account. The following traces the development of one such technique.

\section{Problem Statement}

A piece of equipment is a combination of line replaceable units assembled together that are normally capable of independent operations $[12,13]$. Such units or groups of units within a plant may be replaced or repaired upon failure or during preventive maintenance. The maintenance activity therefore is a periodic cycle of PM and operation time interspersed with possible breakdowns which exist but are random in occurrence [14]. Let $C\left(T_{i}, M\right)$ be the total maintenance cost dependent on the time $T_{i}$ between PM activities and $M$ the number of men assigned to on-site maintenance. Let $\mathrm{A}_{\mathrm{i}}\left(\mathrm{T}_{\mathrm{i}}, \mathrm{M}\right)$ be the availability of group 1 or the fraction of time the subsystem group $\mathrm{i}$ is operational. The time interval of interest is a complete cycle.

Our objective then is to minimize $C\left(T_{i}, M\right)$ subject to

$$
\begin{aligned}
& A_{i}\left(T_{i} M\right) \geq A_{\min }, \quad i=1,2 \ldots N \\
& T_{i} \geq 0 \\
& M_{\min } \leq M \leq M_{\max } \text { integer } \\
& N-\text { is the number of groups in the system. }
\end{aligned}
$$

The sequence is shown following

\begin{tabular}{|c|c|c|}
\hline Time for PM & Operation Time & Time for PM \\
\hline & $\mathrm{T}_{\mathrm{i}}$ (years) & \\
\hline
\end{tabular}

Let $\mathrm{T}_{\mathrm{si}}$ be the mean total man-hours to perform scheduled PM on each unit in group $\mathrm{i}$, where there are $\mathrm{a}_{\mathrm{i}}$ units in group $\mathrm{i}$.

$$
\begin{array}{lll}
\text { Hence time for PM } & = & a_{i} \frac{T_{s i}}{M} \text { hours, } \\
\text { If there are } \mathrm{H} & = & 8760 \text { hours per year, then } \\
\quad \text { PM time } & a_{i} \frac{T_{s i}}{H M} \text { years, } \\
\text { Hence cycle time } & = & \mathrm{T}_{\mathrm{i}}+a_{i} \frac{T_{s i}}{H M} \text { years }
\end{array}
$$

The problem now is that during the interval between PMs, $T_{i}$, we may have unscheduled emergency breakdown maintenance primarily due to unit failure. The unit is therefore available for less than $T_{i}$ years by the time it takes to recognize or detect and locate or diagnose the failure and the time it takes to repair the failure. Let $\mathrm{D}_{i}$ be the downtime per failure of each unit in group. Then

$$
\mathrm{D}_{\mathrm{i}}=\mathrm{T}_{\mathrm{ci}}+\mathrm{T}_{\mathrm{mi}} / \mathrm{M} \text { - hours/failure }
$$

Where $T_{c i}$ is the mean time for failure recognition and diagnosis and $T_{m i}$ is the mean total active repair time in man hours.

Let $E_{i}\left(T_{i}\right)$ be the mean number of failures of each unit in group i during the interval $T_{i}$ then

Total down time in hours

Hence the unit is available

$$
\begin{array}{lll}
=\mathrm{a}_{\mathrm{i}} & \mathrm{D}_{\mathrm{i}} & \mathrm{E}_{\mathrm{i}}\left(\mathrm{T}_{\mathrm{i}}\right)-\text { hours } \\
=\mathrm{a}_{\mathrm{i}} & \mathrm{D}_{\mathrm{i}} & \mathrm{E}_{\mathrm{i}}\left(\mathrm{T}_{\mathrm{i}}\right) / \mathrm{H}-\text { years, }
\end{array}
$$

$$
\mathrm{T}_{\mathrm{i}}-\mathrm{a}_{\mathrm{i}} \mathrm{D}_{\mathrm{i}} \mathrm{E}_{\mathrm{i}}\left(\mathrm{T}_{\mathrm{i}}\right) / \mathrm{H}-\text { years, }
$$

By definition availability is thus given by dividing equation (6) by equation (3).

$$
A_{i}\left(T_{i}, M\right)=\frac{T_{i}-a_{i} D_{i} E_{i}\left(T_{i}\right) / H}{T_{i}+a_{i} \frac{T_{s i}}{H M}} ; i=1,2, \ldots N
$$

Let $\lambda_{\mathrm{i}}(\mathrm{t})$ be the general failure rate of each line replaceable unit. It can be generally be expressed as

$$
\lambda_{i}(t)=\lambda o_{i}+\lambda 1_{i . t}
$$

that is, the sum of a constant value independent of time and a component that is dependent on time. The mean number of failures of each unit in group 1 during time period $T_{i}$ is given by

$$
\begin{aligned}
E_{i}\left(T_{i}\right) & =\int_{0}^{T_{i}} \lambda_{i}(t) d t \\
& =\lambda_{\text {oiTi }}+1 / 2 \lambda_{1 i}\left(T_{i}\right)^{2}
\end{aligned}
$$


Total Maintenance Cost - Rate

The total maintenance cost-rate is the sum of the total downtime cost-rate, $\mathrm{Cd}$ of the system, the total wage-rate of maintenance manpower, $\mathrm{Cm}$ and the total set-up cost of $\mathrm{PM}, \mathrm{Cpm}$. There are two components in the downtime cost-rate.

$N$

1. $\sum \mathrm{C}_{\mathrm{dvi}}\left(\mathrm{T}_{\mathrm{i}}, \mathrm{M}\right)$, downtime cost-rate of the system during unscheduled emergency failures)

$i=1$

$N$

2. $\sum \mathrm{C}_{\mathrm{dsi}}\left(\mathrm{T}_{\mathrm{i}}, \mathrm{M}\right)$, downtime cost-rate of the system to scheduled shutdowns for PM

$$
i=1
$$

Using earlier definition then

$$
\begin{array}{ll}
\mathrm{C}_{\mathrm{dvi}}\left(\mathrm{T}_{\mathrm{i}}, \mathrm{M}\right) & =\mathrm{a}_{\mathrm{i}} \mathrm{D}_{\mathrm{i}} \mathrm{E}_{\mathrm{i}}\left(\mathrm{T}_{\mathrm{i}}\right) \mathrm{Cd} / \mathrm{T}_{\mathrm{i}} \\
\mathrm{C}_{\mathrm{dsi}}\left(\mathrm{T}_{\mathrm{i}}, \mathrm{M}\right) & =\mathrm{a}_{\mathrm{i}} \mathrm{T}_{\mathrm{si}} \mathrm{Cd} /\left(\mathrm{T}_{\mathrm{i}}, \mathrm{M}\right)
\end{array}
$$

The set-up cost-rate for group $i$, and the wage-rate are

$$
\begin{array}{lll}
\mathrm{Si} & = & \mathrm{Cpm} / \mathrm{T}_{\mathrm{i}} \\
\mathrm{W} & = & \mathrm{MCm}
\end{array}
$$

Hence the total maintenance cost-rate is

$$
\mathrm{C}\left(\mathrm{T}_{\mathrm{i}}, \mathrm{M}\right)=\quad \mathrm{W}+\sum_{i=1}^{\sum\left(\mathrm{C}_{\mathrm{dvi}}+\mathrm{C}_{\mathrm{dsi}}+\mathrm{S}_{\mathrm{i}}\right)}
$$

Subject to the constraints:

$$
\begin{aligned}
& \mathrm{A}_{\mathrm{i}}\left(\mathrm{T}_{\mathrm{i}}, \mathrm{M}\right) \quad=\frac{T_{i}-a_{i} D_{i} E_{i}\left(T_{i}\right) / H}{T i+a i \frac{T_{s i}}{H M}} \quad \mathrm{~A}_{\min }, \mathrm{i}=1,2 \ldots \mathrm{N} \\
& \mathrm{T}_{\mathrm{i}} \geq 0, \mathrm{i}=1,2 \ldots \mathrm{N} \\
& \mathrm{M}_{\min } \leq \mathrm{M} \leq \mathrm{M}_{\max }, \text { integer }
\end{aligned}
$$

\section{Assumptions}

1. The failure rates of the equipment are all available

2. The mean time parameters $T_{\mathrm{ci}}, \mathrm{T}_{\mathrm{mi}}, \mathrm{T}_{\mathrm{si}}$ are available, $\mathrm{T}_{\mathrm{ci}}$ is independent of the number of men.

3. The PM is extensive enough as to reset failure rates to original value. The PM does not damage any part of the system.

\section{Solution Technique}

This is a search algorithm consisting of the following steps:

1. Each optimum value of Ti for each group of items is obtained by setting the partial derivative of $\mathrm{C}\left(\mathrm{T}_{\mathrm{i}}, \mathrm{M}\right)$ with respect to $\mathrm{T}_{\mathrm{i}}$, to zero. This yield

$$
\mathrm{T}_{\mathrm{i}}=\left[\frac{2 \mathrm{Tsi}}{\lambda \mathrm{li}_{\mathrm{i}} \overline{\mathrm{D}}_{\mathrm{i}} \mathrm{M}}+\frac{2 \mathrm{Cpm}}{\mathrm{C}_{\mathrm{d}} \mathrm{a}_{\mathrm{i}} \lambda 1_{\mathrm{i}} \mathrm{D}_{\mathrm{i}}}\right]^{1 / 2}
$$

Note that this depends on $\mathrm{M}$ an unknown value.

2. Tabulate results of $\quad T_{i}, A_{i}\left(T_{i}, M\right)$,

$$
C_{d v i}\left(T_{i}, M\right), C_{d s i}\left(T_{i}, M\right) \text { by assuming an integer value of } M \text { varying from } M_{\min } \text { to } M_{\max } \text {. }
$$

3 .The total maintenance cost-rate $C\left(T_{i}, M\right)$ is calculated for the range of integer values of $M$.

4. The value of $M$ giving the lowest value of $C\left(T_{i}, M\right)$ is found from the calculations of step 3. The corresponding values of optimum $T_{i}$ are found from the tabulations of step 2. The constraints $A_{i}\left(T_{i}, M\right)$ are checked in each case and must be satisfied. 


\section{Example Application}

The following example illustrates the application of the above optimization technique to coal mine power equipment. The input data is as specified in Table 1 and Table 2.

TABLE 1

INFORMATION ON MINE POWER-EQUIPMENT FOR OPTIMAL MAINTENANCE SCHEDULING

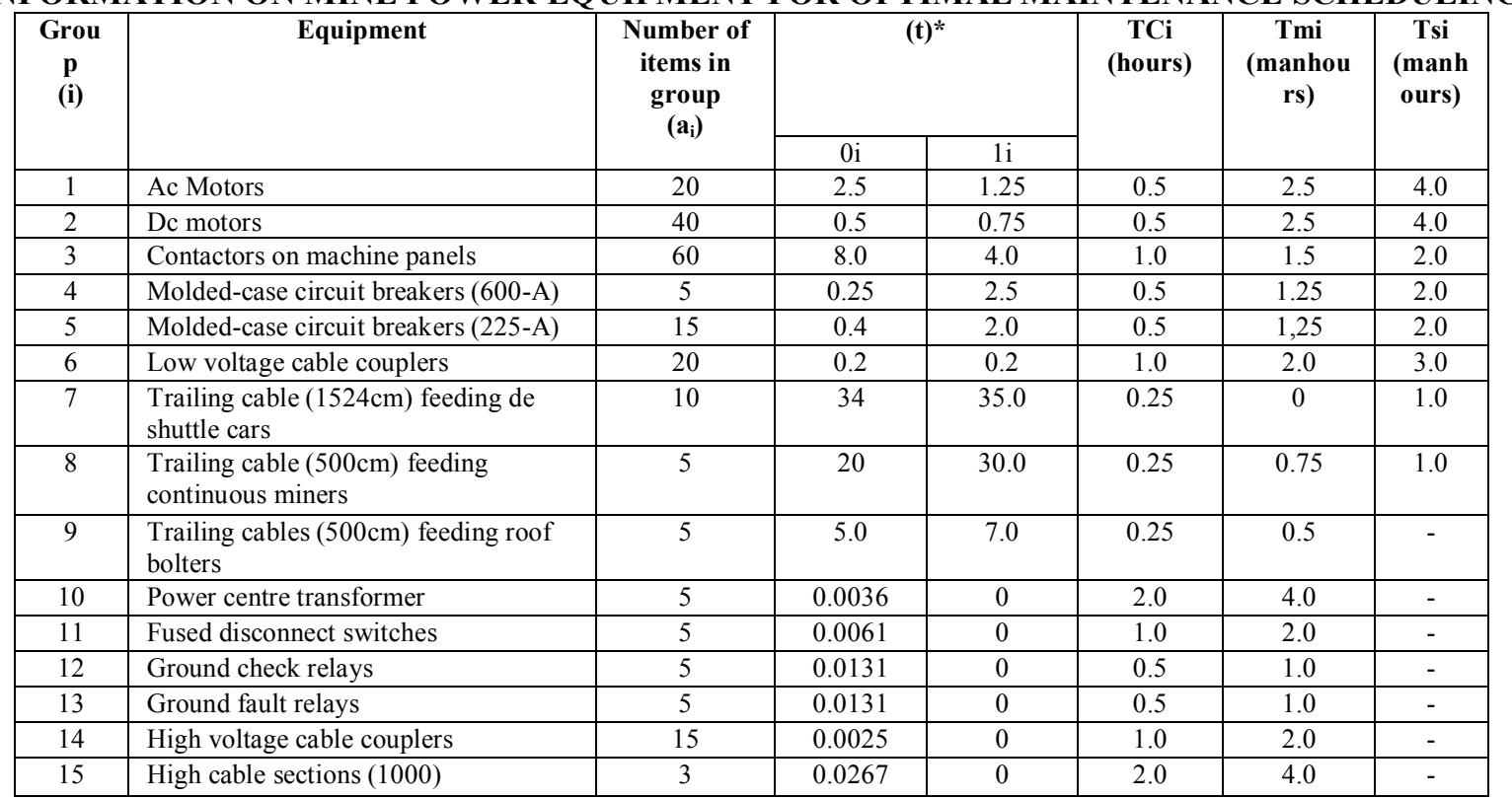

TABLE 2

COST AND CONSTRAINT INFOMRMATION ON EXAMPLE SYSTEM

\begin{tabular}{|l|l|}
\hline Parameter & Value \\
\hline Cost of downtime, $\mathrm{c}_{\mathrm{d}}$ & $\$ 50 /$ hour \\
\hline Cost of inspection set up, $\mathrm{C}_{\mathrm{pm}}$ & $\$ 100 /$ set-up \\
\hline Wages - rate, $\mathrm{C}_{\mathrm{m}}$ & $\$ 2000 /$ man-year \\
\hline Minimum, availability needed, $\mathrm{A}_{\min }$ & 0.9 \\
\hline Minimum number, $\mathrm{M}_{\min }$ of maintenance men required & 5 \\
\hline Maximum number, $\mathrm{M}_{\max }$, of maintenance men & 10 \\
\hline
\end{tabular}

Results obtained by use of a search technique yielded the values of optimum intervals between PMs and the number of men required as shown in Table 3 and Table 4.

1. Optimum number of men, M:7

2. Minimum total annual maintenance cost: $\$ 625.7$

3. Optimum PM intervals, $\mathrm{T}_{\mathrm{i}}$, are given below

TABLE 3

RESULTS OF APPLYING MAINTENANCE PROGRAM TO THE SYSTEM

\begin{tabular}{|c|l|c|}
\hline Group & \multicolumn{1}{|c|}{ Equipment } & Optimum \\
\hline 1 & \multicolumn{1}{|c|}{ (days) } \\
\hline 2 & ac motors & 380 \\
\hline 3 & dc motors & 488 \\
\hline 4 & contactors on machine panels & 126 \\
\hline 5 & molded-case circuit breakers (600-A) & 226 \\
\hline 6 & molded-case circuit breakers (225-A) & 242 \\
\hline 7 & low-voltage cable couplers & 674 \\
\hline 8 & de shuttle car training cables (1524cm) & 62 \\
\hline 9 & continuous miner trailing cables (1524cm) & 67 \\
\hline 10 & poof bolter training cables (1524cm) & 147 \\
\hline 11 & fused disconnect switches & $*$ \\
\hline 12 & ground check relays & $*$ \\
\hline 13 & ground fault relays & $*$ \\
\hline 14 & high-voltage cable couplers & $*$ \\
\hline 15 & high-voltage cable sections (38480cm) & $*$ \\
\hline
\end{tabular}

*Emergency repairs only. No PM 
TABLE 4

OPTIMAL INTERVAL BETWEEN PMS AND NUMBER MEN

\begin{tabular}{|c|c|}
\hline Men, $\mathbf{M}$ & Total maintenance cost - rate, $\mathbf{C}\left(\mathbf{T}_{\mathbf{i}}, \mathbf{M}\right) \mathbf{\$ 1 0} / \mathbf{y e a r}$ \\
\hline 5 & 6.72 \\
\hline 6 & 6.58 \\
\hline 7 & 6.53 \\
\hline 8 & 6.54 \\
\hline 9 & 6.59 \\
\hline 10 & 6.67 \\
\hline
\end{tabular}

\section{Conclusion}

Research in maintenance scheduling is of great importance because of the large number of subsystems and components which are subject to failures.

Herein, maintenance cost rate associated with the use of manpower and equipment for a large establishment was studied. A maintenance work request flow chart was used to schedule the work order in order to ascertain the maintenance job priority assignment task. The subsystems and components were mathematically optimized and scaled down so as to obtain the optimal preventive maintenance periods and the number of men required to perform the preventive maintenance. Results obtained showed a minimized maintenance cost rate as summarized in the Table 4.

\section{References}

[1] Jardine, A. K. S., Maintenance, Replacement and Reliability, Pitman Publishing (reprinted editions available from Canadian Scholar Press, Inc. 211 Grenadier Road, Toronto, Ontario, Canada) 1973

[2] Sim, S. H., and Endrenyi, J, Optimal Preventive Maintenance with Repair, IEEE Trans., 1988 Vol. R-37, No. 1., Pp. 92-96.

[3] Anders, G. J., Human Failure Considerations in determining Optimal Inspection Interval for the Equipment Used in Emergency Conditions, IEEE Trans., 1985 Vol. SMC-15, No. 2, pp. 290-294.

[4] Apostolakis, G. E. and Bansal, P. P. Effect of Human Error on the Availability of Periodically Inspected Redundant Systems, IEEE Trans., 1977 , Vol. R-26, No. 3, pp. 220-225.

[5] Barlow, R. E., and Hunter, L. Optimum Preventive Maintenance Policies, Oper. Res., 1960, Vol. 8, pp. 90-100

[6] Gaertner, J. P. , Morgan, T. A., and Rodin, M. E. Insights Gained Through the Implementation of Reliability Centred Maintenance Practices at Nuclear Power Plants, in Proceedings of the 15th Inter-Ram Conference, Portland, Oregon, 1988, pp. 70-74

[7] Anders, G. J., Inspection Frequency and Availability of Emergency Equipment, Microelectron. Reliab., 1984 Vol. 24, No. 4, pp. $683-690$.

[8] Keeney, R. L., Beley, J. R., Fleischauer, P., Kirkwood, C. W., and Sicherman, A. (1981), Decision Framework for Technology Choice. Vol. 1: A Case Study of One Utility's Coal-Nuclear Choice, Electric Research Power Institute Report No. EA-2153.

[9] Leitl, R., and Machek, J. On Optimum Preventive Maintenance Philosophy, Shoda Works, Nuclear Power Construction Division, Information Center, Report No. ZJE-274, 1986 Pilzen, Czechoslovakia.

[10] McWilliams, T. P. and Martz, H. F. Human Error Considerations in Determining the Optimum Test Interval for Periodically Inspected Standby Systems, IEEE Trans., 1980 Vol. R-29, No. 4 pp. 305-310

[11] Endrenyi, J., and Sim, S. H. (1988), Availability Optimization for Continuity Operating Equipment with Maintenance and Repair, in Proceedings of the $2^{\text {nd }}$ International Symposium on Application of Probability Methods in Electric Power System, San Fransisco, California.

[12] Cleroux, R., Dubuc, S., and Tiquin, C., The Age Replacement Problem with Minimal Repair and Random Repair Costs, OPer. Res., 1979 Vol. 27, pp. $1158-1167$.

[13] Howard, R. A. (1960) Dynamic Programming and Markov Processes, John Wiley and Sons, New York.

[14] Sim, S. H. Reliability of Standby Equipment with Periodic Testing, IEEE Trans., 1987, Vol. R.36, No 1, pp. 117 - 123 